Cite this: J. Anal. At. Spectrom., 2014, 29,152

\title{
Effects of methane addition to nebulizer gas on polyatomic interferents and ion sensitivity in inductively coupled plasma mass spectrometry
}

\author{
Rui Santos
}

The addition of methane to nebulizer gas was assessed as a method for the reduction of polyatomic interferents in inductively coupled plasma mass spectrometry (ICP-MS). The effects of nebulizer gas flow rate, $\mathrm{RF}$ power and methane flow were studied for a range of analytes and polyatomic ions. The analyte sensitivity, especially for $\mathrm{Be}, \mathrm{Br}$ and $\mathrm{I}$, was enhanced by a factor of 7-12 with methane addition. Polyatomic ions, such as $\mathrm{ArCl}^{+}, \mathrm{ArO}^{+}, \mathrm{ClO}^{+}$and $\mathrm{ArArH}^{+}$, were reduced between 61 and 92\% when compared to those of an unmodified plasma. Such reduction allowed better quantification limits for $\mathrm{V}$, $\mathrm{As}, \mathrm{Se}, \mathrm{Br}$ and $\mathrm{I}$, as well as $90 \% \mathrm{BaO}^{+}$polyatomic reduction. Finally, the optimized conditions were evaluated in successful recovery tests for As, Se and $\mathrm{V}$ in different matrices with high chloride content. The Fe accuracy was evaluated in several reference materials.

Received 4th July 2013

Accepted 9th October 2013

DOI: $10.1039 / c 3 j a 50221 j$

www.rsc.org/jaas such as nitrogen, ${ }^{14-17}$ oxygen, ${ }^{18}$ hydrogen, ${ }^{17,19}$ helium ${ }^{20-22}$ and carbon-containing solvents, have been studied using solution nebulization ICP-MS. For example, Sheppard et al..$^{22}$ found that addition of He produces a plasma capable of ionizing elements with high ionization potential more efficiently than pure $\mathrm{Ar}$ plasma. Evans and Ebdon ${ }^{23,24}$ reported the addition of nitrogen and oxygen to the nebulizer gas with a significant reduction of $\mathrm{ArCl}^{+}$. Lam and Horlick ${ }^{25}$ reported that polyatomic interferents can also be reduced and the sensitivity of analytes can be improved by adding nitrogen to the auxiliary gas flow. Lam and McLaren $^{26}$ found that the $\mathrm{UO}^{+} / \mathrm{U}^{+}$ratio and $\mathrm{ArO}^{+}$intensities were reduced by adding $8 \%$ nitrogen to the auxiliary gas, and they also reported interferents reduction on Fe and Se. The optimization of nitrogen addition to the nebulizer and auxiliary gas flows, reported by Hill et al., ${ }^{27}$ revealed a dramatic reduction of $\mathrm{ArCl}^{+}$and $\mathrm{ClO}^{+}$interferents on As and $\mathrm{V}$, respectively.

More recently, most studies have focused on the addition of other gases. Smith et al. ${ }^{28}$ investigated the addition of Xe to the nebulizer gas and reported a reduction in polyatomic interferents. Allain et $a .^{29}$ added methane to the nebulizer gas and verified improvement in the sensitivity of most analytes. However, addition of organic compounds to the ICP, either as admixtures to the gas phase or C-based additives to the sample solution, has a disadvantage: they will produce other kinds of polyatomic interferents, such as $\mathrm{CN}^{+}, \mathrm{CO}^{+}, \mathrm{ArC}^{+}$, etc., especially below $\mathrm{m} / z 53$.

Since the first use of mixed gases, it has been observed that even small amounts of additives change significantly the $\mathrm{Ar}$ plasma properties. ${ }^{30}$ Among other effects, the shape or geometry of the plasma is affected in these mixed gas plasmas, ${ }^{13,25}$ which subsequently affects the ion extraction or sampling efficiency of ions through the sampler cone. It has also been reported that an increased amount of hydrogen in carbon containing plasmas, 